\title{
La centro-izquierda, el corporativismo empresarial y las contradicciones internas del Estado desarrollista en Chile, 1932-1954
}

\author{
Center-left parties, businessmen and contradictions in the developer state in \\ Chile, 1932-1954
}

Mauricio Casanova Brito*

Resumen: El propósito del presente artículo es cuestionar la tesis del Estado de compromiso en Chile, según la cual el modelo desarrollista (1932-1954) habría sido el resultado de una coalición entre diferentes clases sociales, en la cual el Estado era concebido como un espacio de conciliación entre distintos intereses. En el artículo se pone en evidencia que, lo que la centroizquierda comúnmente ha considerado como un Estado fuerte e intervencionista, era en realidad un poder ejecutivo debilitado e incapaz de administrar sus propios recursos de forma autónoma.

Palabras clave: Chile, Estado desarrollista, asociaciones empresariales, Centro-izquierda

\begin{abstract}
The main aim of this article is to call into question the compromise-state thesis in Chile, based on the idea that the so-called developmental model (1932-1954) was the result of a multi-class coalition, in which the state was conceived as a space of conciliation of different social interests. The article shows that what the center-left often considered to be a strong and interventionist state, was in reality a weak executive power, unable to self-manage its own resources.
\end{abstract}

Key words: Chile, developmental state, business associations, Centre-left forces

Recibido: 3 septiembre 2018 Aceptado: 18 octubre 2018

\section{Introducción}

Tanto historiadores como economistas coinciden en que la característica elemental del periodo 19381954 en Chile fue el desenvolvimiento del denominado Estado desarrollista. Este se habría expresado, en el plano económico, en políticas de industrialización por sustitución de importaciones, la orientación hacia el mercado interno y la implementación de programas de desarrollo a largo plazo. En lo social, habrían destacado las políticas de aumento salarial, la expansión de la cobertura educativa y de salud, además del incremento de las pensiones y la seguridad social. Ambas expresiones de este modelo, el desarrollo económico y el bienestar social, se habrían llevado a cabo a partir de la cooperación entre

* Chileno. Licenciado en Historia, Universidad de Concepción (2011); Magíster en Filosofía, Universidad de Chile (2014); Doctor en Historia Contemporánea, Universidad Libre de Berlín (2018). Email: m.casanovabrito@gmail.com 
diversos actores, incluyendo los partidos políticos de centro-izquierda, los gremios empresariales, la burocracia técnica, los institutos científicos y el mundo sindical. El Estado desarrollista - caracterizado por Meller como promotor, empresario y programador ${ }^{1}$ - habría sido entonces una instancia de conciliación de intereses entre actores sociales de diversa procedencia, en los que habría existido cierto consenso con respecto a las necesidades nacionales. ${ }^{2}$

En este artículo se intenta poner en cuestión esta tesis de la cooperación, frecuente en la mayor parte de la bibliografía ${ }^{3}$; evidenciando que la idea del supuesto consenso nacional desarrollista no es tanto una tesis de interpretación historiográfica, sino más bien un supuesto perteneciente al discurso de la misma centroizquierda de aquella época. Si se analiza críticamente el periodo, lo que se asume comúnmente como cooperación aparece más bien como la consolidación de un dogma, desarrollado por los gremios empresariales en la década de 1930, basado en la idea que los recursos estatales no debían ser gestionados por agentes del Estado, contaminados por intereses partidistas o doctrinas ideológicas. La principal victoria de los círculos empresariales habría sido entonces el posicionar esta idea como parte de un supuesto consenso nacional. Paradójicamente, ha sido la centro-izquierda la principal encargada de extender esta tesis de la cooperación; transformando, discursivamente, en un Estado fuerte e interventor, lo que en realidad era un poder ejecutivo incapaz de administrar sus recursos de manera autónoma o de llevar a cabo programas sociales a largo plazo.

Es complejo establecer un concepto que englobe las fuerzas políticas del denominado periodo desarrollista, debido a dos motivos. En primer lugar, no es posible centrar la definición en partidos políticos de izquierda. El frente popular estaba inicialmente liderado por los partidos radical, socialista y comunista, excluyendo a los partidos liberal y conservador. Pero luego, en las elecciones de 1942, los liberales apoyaron a la Alianza Democrática, en oposición a la candidatura de Ibáñez, considerado un peligro fascista. Ríos intentó incluso formar un gabinete basado en la alianza radicales-liberales, pero el intento fue frustrado por Arturo Alessandri. En el gobierno de González Videla, la denominada ley maldita excluye a los comunistas de cualquier tipo de alianza. Además, el gabinete de Concertación Nacional (1948-1950) contó con ministros liberales y conservadores. En segundo lugar, no se puede establecer una doctrina política específica. Los gobiernos radicales estuvieron caracterizados por una mixtura de influencias, desde el liberalismo hasta el marxismo. Sin embargo, hay una idea que marca fuertemente al periodo y que permite unificar las alianzas políticas de la época en un concepto unitario. Esta se refiere a la convicción que el fomento estatal a la producción, en cooperación con los gremios empresariales y las organizaciones técnico-científicas, es la vía indicada para el incremento del bienestar de la clase trabajadora. Roberto Wachholtz, Oscar Schnake, incluso Ibáñez (en los primeros años de su segundo gobierno), son ejemplos representativos de esta idea. Si bien los mecanismos políticos o alianzas para lograr esta finalidad varían a lo largo del periodo estudiado, esta convicción se mantiene permanente. Por este motivo, hemos afirmado que la tesis del estado de compromiso no es inicialmente una tesis historiográfica, sino parte de un discurso de los mismos actores de la época. Esta convicción, que comienza a forjarse a mediados de la década de 1920, difiere con respecto a las ideas de la Central Única de Trabajadores (1953) y el Frente de Unidad Sindical (1956); entidades en las que se dio preferencia a

\footnotetext{
1 "Primero fue el Estado-promotor, que proporcionaba el crédito para la inversión privada; luego, el Estado-empresario, a través de las empresas estatales; finalmente, el Estado-programador, que definía el horizonte de largo plazo del patrón chileno de desarrollo". Meller, Patricio, Un siglo de economía política chilena 1890-1990, Santiago, Editorial UAB, 1998, p. 59.

2 Por ejemplo, véase: Garreto $\square$ n, Manuel, El proceso poli $\square$ tico chileno, Santiago, Ediciones Minga, 1983; Montero, Cecilia, La revolución empresarial chilena, Santiago, BPR Publishers, 1997; Silva, Patricio, Estado, neoliberalismo y poli tica agraria en Chile, $1973-$ 1981, Amsterdam, CEDLA, 1987; Collier, Simon y Sater, William, A History of Chile, 1808-1994, Cambridge, Cambridge University Press, 1966; Nazer, Ricardo, "La Corporación de Fomento de la Producción y la modernización económica en Chile 1939-1970”, Revista de gestión pública, volumen V, número 2, 2016, pp. 283-316; Rodríguez Weber, Javier, La economía política de la desigualdad del ingreso en Chile 1850-2009, Montevideo, Universidad de la República (Tesis doctoral), 2014, pp. $259-287$.

3 Para un análisis crítico de bibliografía del supuesto estado de compromiso en Chile, véase: Clark, Timothy David, The estate and the making of the capitalist modernity in Chile, Toronto, York University (tesis doctoral), 2012.
} 
una postura clasista, rechazando alianzas con los denominados reformistas de centro. En este artículo, nos referimos a centro-izquierda en base a esta definición histórica, evitando restringir el término a partidos, gobiernos, alianzas o doctrinas.

Nuestra hipótesis se basa en cinco puntos: primero, que para realizar un análisis crítico en torno al denominado Estado desarrollista, es necesario diferenciar administración estatal de financiamiento estatal; segundo, que al considerar esta distinción, el Estado desarrollista aparece no como un Estado homogéneo, sino como uno dividido, pues el Estado empresario era administrado y financiado de una forma distinta al Estado social'; tercero, que el supuesto estilo cooperativo de la clase empresarial tuvo lugar solamente en el Estado empresario, pero no en el social; cuarto, que esta supuesta voluntad cooperativa de la clase empresarial en el Estado empresario era, en la práctica, la defensa de una idea - que surge en 1936-1938 - que sugiere que los recursos del Estado no debiesen ser administrados por agentes del Estado; quinto, que el des-financiamiento y la debilidad del Estado social fueron las causas determinantes de la crisis del modelo desarrollista corporativista.

El artículo se divide en tres secciones. En la primera, se analiza el cambio de doctrina de los círculos empresariales en el periodo 1932-1938, en donde se transita desde la defensa de un Estado empresario comandado por un gobierno acorde a los intereses de la producción y el comercio, a la idea que el problema no es el tipo de gobierno, ni la ideología, ni el partido, ni el presidente, sino el mismo poder ejecutivo. Para la Confederación de la Producción y el Comercio (CPC), los recursos estatales destinados al fomento económico no debían ser gestionados por partidos contaminados por pasiones ideológicas, sino por instancias técnicas corporativas. La idea central era no tanto la de colaborar con la formación de un Estado moderno o empresario, como se suele pensar ${ }^{5}$, sino la de reducir al máximo la incidencia de los poderes ejecutivo y legislativo en la gestión de los recursos públicos destinados al fomento. Además, se examina cómo la estrategia de financiamiento al fomento empresarial del periodo 1933-1938, los préstamos directos e indirectos del Banco Central, se estanca en el periodo 1936-1938 debido tanto a la inflación como a la reorganización de las fuerzas de izquierda.

En la segunda sección, se estudia la forma en que el proyecto político-empresarial de la CPC logra ser implementado a pesar de convivir con un programa de centro-izquierda. En este proceso, la convicción de la centro-izquierda de la Corporación de Fomento de la Producción (Corfo) como una instancia de conciliación entre clases antagónicas es fundamental. El examen inicia poniendo en evidencia la manera en que sectores políticos diametralmente opuestos coincidieron en que el proyecto de la Corfo significaba una reducción del campo de acción para los poderes ejecutivo y legislativo. Luego, se analizan las numerosas redes indirectas de los círculos empresariales en el sector público, que ponen en cuestión la idea del Estado desarrollista como un equilibrio de poderes. Se llega a la conclusión que lo novedoso del periodo desarrollista post-1939, no es tanto la formación del Estado empresarial - cuyos orígenes pueden datarse incluso hasta inicios del siglo XX - sino la consolidación de un modelo sustentado en la administración no-estatal de los recursos estatales.

En la tercera sección, se indaga en el otro lado del Estado desarrollista: el Estado social. Este, al contrario del Estado empresario, no estaba administrado por organismos corporativos semi-autónomos, como la Corfo, sino por los gobiernos de turno, los que tuvieron que enfrentar continuamente la nocooperación tanto del poder legislativo como de los gremios empresariales. Tampoco estaba financiado con recursos del cobre o empréstitos extranjeros, como en el caso de las políticas de fomento, sino con

\footnotetext{
4 También se le ha denominado Estado de seguridad social: "Llamarlo Estado de Bienestar es un término muy amplio. Respecto de América Latina, la literatura especializada ha preferido el nombre de Estado de Seguridad Social", Rengifo, Francisca, "El estado de seguridad social chileno y la institucionalización desigual del bienestar” en Rengifo, Francisca, Jaksin, Iván (eds.), Historia politica de Chile, 1810-2010. Tomo II: Estado y sociedad, Chile, FCE Chile, 2017, p. 397.

5 Por ejemplo: Ibáñez Santa María, Adolfo, "Los ingenieros, la política y la política en Chile: del ministerio de fomento a la Corporación de Fomento de la Producción 1927-1939", Historia, número 18, 1983, pp. 45-102; Ibáñez, Santa María, Adolfo, "El liderazgo de los gremios empresariales y su contribución al desarrollo del Estado moderno durante la década de 1930", Historia, número 28. 1994, pp. 183-216.
} 
impuestos temporales, que con frecuencia resultaban insuficientes. Por este motivo, para enfrentar los déficits fiscales del periodo 1949-1954, provocados por el incremento del gasto social, los gobiernos se vieron forzados a recurrir a los préstamos del Banco Central, ocasionando graves presiones inflacionarias. Es decir, que la estrategia de financiamiento al sector empresarial del periodo 1933-1938, desechada desde 1939 por los círculos empresariales debido a sus consecuencias inflacionistas, termina convirtiéndose en un recurso de última instancia para el Estado social. Se finalizado evidenciando que el des-financiamiento del Estado social y la ausencia da una política nacional de cooperación - situación diametralmente opuesta a la supuesta conciencia nacional existente en el Estado empresario - fue lo que finalmente desencadena la crisis inflacionaria; y que este Estado social no era excesivamente intervencionista, sino débil y carente de programas.

\section{Del Estado empresario a los empresarios en el Estado: las propuestas de los gremios empresariales 1932-1938}

A principios de 1932, en el contexto del intenso descontento social provocado por la crisis económica internacional, la Sociedad de Fomento Fabril (Sofofa), pretendiendo ser la voz del mundo empresarial de la época, elabora una propuesta de reformas estructurales, para ser presentada ante los organismos públicos. En este Plan de industrialización, el gremio industrial forja las bases del modelo de fomento al sector empresarial instaurado posteriormente durante el gobierno de Arturo Alessandri (19321938). Este programa estaba basado en tres aspectos. Primero, se propone explícitamente la implementación de un plan de industrialización por sustitución de importaciones. Se consideraba, como fue común en la época, que los efectos devastadores de la crisis podrían ser evitados en el futuro disminuyendo la dependencia económica con respecto al mercado exterior. El modelo primarioexportador, orientado bacia afuera, debía ser reemplazado por un modelo desarrollista, orientado hacia adentro. El proyecto iniciaba haciendo un llamado a "exportar más y reemplazar artículos de importación por producción nacional. Para esto último tenemos materias primas o podemos producirlas. Y nos falta solamente crear los medios que nos permitan llevarlos a la práctica". ${ }^{6}$

En segundo lugar, la Sofofa propuso cambiar el modelo de financiamiento vigente hasta la crisis. En vez de recurrir a los capitales estadounidenses para impulsar el proceso de modernización, como fue común en la década de $1920^{7}$, el gremio de la manufactura abogaba por la utilización indirecta de los recursos del Banco Central. No se intentaba hacer uso de los recursos de oro de la entidad, sino de la posibilidad de emitir circulante monetario. Los problemas inflacionarios que provocaría el incremento de circulante, serían contrastados con crecimiento económico e industrialización: "No propiciamos en forma alguna el empleo directo de los depósitos en oro del Banco Central en un plan de industrialización del país, pero insinuamos una solución que permita emplear estos fondos transitoriamente como garantía en el pago de elementos necesarios para reconstruir nuestra economía nacional". 8

En tercer lugar, se consideraba que el modelo ISI debía ser administrado por los institutos semifiscales de crédito creados en la década anterior, como el Instituto de Crédito Industrial o la Caja de Crédito Minero, evitando el denominado industrialismo de Estado. Es decir, eludiendo la creación de empresas o industrias controladas directamente por agentes estatales. Los institutos semi-fiscales de crédito eran sociedades anónimas, cuyos directorios estaban conformados por gremios empresariales, ministros del gobierno de turno e institutos científicos. Habían sido creados en su mayoría durante el régimen de Carlos Ibáñez del Campo (1927-1931), en concordancia con las ideas corporativistas de la

\footnotetext{
${ }^{6}$ Boletin de la Sociedad de Fomento Fabril (BSFF), mayo de 1932, p. 214.

7 Bernedo, Patricio, "Prosperidad económica bajo Carlos Ibáñez del Campo, 1927-1929: la dimensión internacional de un programa económico de gobierno", Historia, no 105, 1989, 5-105

8 Ibíd., p. 5.
} 
época. Estas organizaciones, en conjunto con las industrias nacionales existentes, debían ser - en consideración de los gremios empresariales - los ejecutores de las políticas ISI. "No pensamos en la creación de una industria del Estado y creemos que el camino indicado sería el de facilitar las garantías de preferencia a industrias nacionales establecidas [...] Las instituciones de crédito que hemos mencionado ejercerían el control usual sobre la debida adquisición de las maquinarias y sobre el funcionamiento de las industrias que con ellas se creen"”.

Si bien este sistema fue implementado provisoriamente durante la República Socialista ${ }^{10}$, fue durante el posterior gobierno de Arturo Alessandri (1932-1938) cuando las propuestas de la Sofofa se transforman definitivamente en política pública. En junio de 1933, se promulga una ley para forzar al Banco Central a emitir circulante con dos propósitos: otorgar préstamos a los institutos semi-fiscales de crédito e iniciar el proceso de liquidación de la Compañía de Salitre de Chile (Cosach). Estos créditos fueron incrementados en noviembre de 1933 y febrero de 1934, siendo la Caja de Crédito Minero y la Caja de Crédito Agrario los institutos semi-fiscales más beneficiados. ${ }^{11}$

Mediante este sistema de fomento - en conjunto con otros factores - la economía chilena logró en pocos años alcanzar, e incluso superar, las cifras de producción anteriores a la crisis. Este proceso, además, habría sido "resultado de un esfuerzo netamente nacional, sin ayuda directa, en absoluto, del extranjero"12. Las autoridades consideraban, por tanto, que "uno de los más saludables efectos que la crisis trajo al país, fue el cierre de los mercados extranjeros de capitales de préstamo". ${ }^{13}$ En 1935, un delegado comercial británico en Chile, sostuvo que: "el denominado periodo normal [1929-1930] fue en realidad quizás un periodo de enforia comerciar [over-trading], basado no solamente en la inflación de los precios internacionales sino también en politicas de crédito irresponsables. En este sentido, se debe recordar la extravagante cantidad de préstamos externos solicitados por Chile"14. El modelo de industrialización por sustitución de importaciones, propuesto inicialmente por los círculos empresariales en 1932 y puesto en marcha desde 1933, parecía entonces tener éxito.

No obstante, este ciclo de recuperación fue breve. A mediados de la década de 1930, las consecuencias imprevistas de este modelo de fomento comenzaban a aparecer. Las continuas emisiones de circulante por parte del Banco Central, utilizadas para proveer capitales al sector empresarial, provocaron un brusco aumento del costo de la vida, siendo los sectores asalariados los más afectados. Las organizaciones obreras denunciaron permanentemente este problema, el que con los años - como afirma Vergara Marshall ${ }^{15}$ - se convierte en una de las principales demandas de la izquierda. Cuando se forma la Confederación de Trabajadores de Chile (CTCH), a fines de 1936, el problema del costo de los

\footnotetext{
${ }^{9}$ Ibíd., p. 6.

${ }^{10}$ Mediante el decreto número 127 (julio de 1932), se forzó al Banco Central a emitir circulante para conceder préstamos a la Caja de Crédito Agrario, a la Caja de Crédito Minero, al Instituto de Crédito Industrial y a la Caja de Colonización Agrícola. Además, esta estrategia crediticia fue usada para enfrentar el déficit fiscal. El Banco Central se vio obligado a comprar tanto vales del tesoro como bonos de deuda de la Compañía de Salitre de Chile. Véase: Memoria Anual del Banco Central de Chile (1932), pp. $1-10$.

11 Diario oficial de la República de Chile, Ley 5.185 publicada el 30 de junio de 1933; Ley 5.307 publicada el 25 de noviembre de 1933. Véase también: Memoria anual del Banco Central de Chile (1934).

12 Memoria annual del Banco Central de Chile (1934), p. 14.

13 Memoria annual del Banco Central de Chile (1934), p. 13.

14 “The so-called normal period [1929-1930] was perhaps in reality one of over-trading, based not only on inflated World prices, but also on irresponsible credit policies. In this connection, one should remember the extravagant borrowing by Chile". John Mitcheson en United Kingdom. Department of Overseas Trade, Report on economic and comercial conditions in Chile, London, 1936, p. 7.

15 "Frente a la inflación y la especulación, el precio justo de los productos de primera necesidad adquirió gran relevancia en el discurso de los partidos políticos de izquierda y de las organizaciones sindicales, motivando numerosas manifestaciones públicas contra las alzas o el desabastecimiento", Vergara Marshall, Ángela, "Estado, trabajo y trabajadores", en Rengifo, Francisca y Jaksic, Iván (eds.), Historia politica de Chile, 1810-2010. Tomo II: Estado y sociedad, Chile, FCE Chile, 2017, p. 388. Véase también: Henríquez, Rodrigo, En estado sólido: políticas y politización en la construcción estatal. Chile 1920-1950, Santiago, Ediciones PUC, 2014, p. 189.
} 
productos de primera necesidad fue considerado como una de las dificultades más apremiantes de la clase trabajadora: "Después de 126 años de vida republicana e independiente de nuestro país [...] asistimos a una total desvalorización de la moneda, al encarecimiento de las subsistencias que jamás antes habíamos presenciado"16. Las denuncias fueron constantes también en los partidos que dieron vida al Frente Popular. La prensa socialista, por ejemplo, consideraba que "nada ha hecho el gobierno actual por poner remedio a los males que aquejan a nuestro pueblo. Nada por solucionar la aflictiva situación de los traficantes y especuladores que se enriquecen a expensas de la miseria popular". ${ }^{17}$ En 1936, el sindicato de estucadores, de forma similar, aseveraba que:

La resurrección espiritual del proletariado se ha manifestado en forma clara y elocuente a través de una serie de movimientos huelguísticos mejorativistas algunos y otros de solidaridad proletaria. Las pesadas cargas tributarias, que, unida a la inobjetable desvalorización del poder adquisitivo de la moneda, de la torpe y amparada especulación de los artículos de primera necesidad, las nuevas leyes tributarias que gravitan pesadamente sobre los escasos emolumentos proletarios, han hecho germinar de los explotados la idea grandiosa de reivindicaciones integralmente ${ }^{18}$

Los gremios empresariales, en tanto, se mostraban insatisfechos frente a la actitud condesendiente de las autoridades, que no lograban terminar con las continuas protestas, iniciadas en 1935 por los trabajadores ferroviarios, pero que luego adquieren alcance nacional. ${ }^{19}$ Para la Sofofa, "las perturbaciones del orden público se traducen inmediatamente en una paralización de la producción y del comercio, en una restricción del crédito, en una baja de todos los valores, en un acaparamiento de los artículos de consumo indispensables y en el encarecimiento general y una detención de toda la actividad económica". ${ }^{20}$

En este panorama de desilusión y de fortalecimiento de la izquierda, las propuestas de industrialización elaboradas en 1932, en el contexto de la crisis, fueron reformuladas. En primer lugar, en un intento por contrarrestar el proceso de reunificación sindical que significó la creación de la CTCH, los gremios empresariales impulsan un proceso similar de reorganización. En 1936, los diferentes gremios de la manufactura, la agricultura, el comercio, la minería y las finanzas se unen en una central nacional: la Confederación de la Producción y el Comercio (1936). Esta entidad había fue el resultado de varios intentos por constituir una instancia de representación nacional de las fuerzas de la producción y el comercio, y había iniciado ya en noviembre de 1933 con la propuesta de una Confederación General de Patrones. ${ }^{21}$

Esta organización siguió enfatizando, al igual que la Sofofa en 1932, los peligros del industrialismo de Estado, la necesidad de estimular los créditos y la inconveniencia tanto del alza de impuestos como del aumento de los salarios. ${ }^{22}$ Pero, junto con estas demandas históricas, se incluye otra sugerencia, inexistente en 1932, y que es fundamental para comprender el modelo instaurado en las décadas posteriores. La CPC elabora una propuesta para conformar un Consejo de Economía Nacional (CEN): una entidad público-privada, gestionada por representantes del gobierno de turno y gremios empresariales, ajena a intereses partidistas, de carácter técnico-científica, que administrase - con programas racionales a largo plazo - los fondos públicos destinados al fomento de la economía. Es decir,

16 La Opinión (26.02.1936). En: Garcés, Mario y Milos, Pedro, FOCH, CTCH, CUT. Las centrales unitarias en la historia del sindicalismo chileno, Santiago, ECO, Educación y Comunicaciones, 1988, pp. 68-69.

${ }^{17}$ La Consigna. Semanario Oficial del Partido Socialista (30.05.1936), p. 3

18 El Andamio. Órgano de la Federación Sindical Libertaria de los Estucados y Ramos Similares (29.02.1936), p. 5.

19 Este proceso de fortalecimiento de la izquierda es analizado en Milos y Garces, FOCH, CTCH, CUT, op. cit., pp. 47-86; Milos, Pedro, Frente Popular en Chile. Su configuración: 1935-1938. Santiago, LOM, 2008; Garces, Mario, Movimiento obrero en la década del treinta y Frente Popular, Santiago, Tesis para optar al grado de Licenciatura en Historia (Pontificia Universidad Católica de Chile), 1985, pp. 68-161.

20 Boletín mensual de la Sociedad de Fomento Fabril (junio 1934), p. 297.

21 Boletín mensual de la Sociedad de Fomento Fabril (noviembre 1933), pp. 1-2.

22 Boletín mensual de la Sociedad de Fomento Fabril (enero 1936), pp. 39-44. 
lo que se sugería era la injerencia de los gremios empresariales en la gestión de los recursos del Estado; que las políticas de fomento, y los fondos destinados a este propósito, no fuesen administrados - en su totalidad - por los poderes ejecutivo y legislativo ${ }^{23}$. La propuesta novedosa no era tanto la de un Estado empresario, como se menciona frecuentemente en la bibliografía ${ }^{24}$, sino la de empresarios en el Estado. El modelo ISI o el proteccionismo no eran una novedad, y sus antecedentes pueden encontrarse incluso en el siglo XIX. ${ }^{25}$ El CEN, en cambio, era una propuesta inédita. El problema ya no era la izquierda o la derecha, los gobiernos civiles o los regímenes militares, liberalismo o estatismo, Alessandri, Ibáñez o Dávila: el problema era el hecho que las políticas de fomento sean gestionadas por los gobiernos de turno, contaminados con intereses partidistas ajenos al bien común.

La CPC estimaba que los partidos políticos estaban anclados en el pasado, e ignoraban la necesidad de construir un modelo basado en la técnica y no en dogmas políticos: "los partidos políticos siguen viviendo en el siglo XIX [...] Es preciso vivir en el siglo actual y estudiar, con espíritu práctico y con pleno conocimiento los hechos, los nuevos problemas". ${ }^{26}$ Por esta razón, el Estado era incapaz, por sí mismo, de plantear un modelo desarrollista basado en programas racionales. Se consideraba que, "por regla general, el Estado es un mal industrial y un pésimo comerciante; jamás la acuosidad y el interés de los particulares podrán ser superados por la organización [...] pesada y tramitadora de los funcionarios fiscales". ${ }^{27} \mathrm{El}$ rol del Estado debía ser el fomento, la provisión de recursos, pero, "tanto la intervención para orientar, impulsar y regular la economía [...] deben ejercitarse por intermedio del Consejo Nacional de Economía".28

Cuadro 1. Modelos de fomento propuestos por los gremios empresariales, Chile 1932-1938

\begin{tabular}{|c|l|l|l|}
\hline Años & Propuesta & Puntos elementales & $\begin{array}{l}\text { Estrategia de } \\
\text { financiamiento }\end{array}$ \\
\hline 1932 & $\begin{array}{l}\text { Plan de Industrialización } \\
\text { de la Sociedad de Fomento } \\
\text { Fabril }\end{array}$ & $\begin{array}{l}\text { Buscar el apoyo del gobierno de Arturo } \\
\text { Alessandri. Elaborar un plan nacional de } \\
\text { fomento basado en políticas ISI. } \\
\text { Evitar la excesiva intervención estatal en la } \\
\text { gestión del plan, dando protagonismo a los } \\
\text { institutos semi-fiscales de fomento ya } \\
\text { existentes }\end{array}$ & $\begin{array}{l}\text { Emisiones del } \\
\text { Banco Central }\end{array}$ \\
\hline $1936-1938$ & $\begin{array}{l}\text { Consejo de Economía } \\
\text { Nacional de la } \\
\text { Confederación de la } \\
\text { Producción y el Comercio la intervención de los poderes } \\
\text { ejecutivo/legislativo en la administración de } \\
\text { los fondos públicos destinados al fomento } \\
\text { de la economía }\end{array}$ & $\begin{array}{l}\text { Recursos } \\
\text { públicos } \\
\text { directos }\end{array}$ \\
\hline
\end{tabular}

De esta manera, las propuestas de 1932, basadas en un modelo ISI gestionado por los institutos semi-fiscales de fomento, financiado con préstamos del Banco Central, e implementado por un gobierno comprometido, son reformuladas en 1936-1938 con la idea del Consejo de Economía Nacional. El problema ya no era el carácter ideológico o el compromiso del gobierno en ejercicio, sino el gobierno mismo.

${ }_{23}$ Con respecto al congreso, se afirmaba lo siguiente: "No queremos atribuir la responsabilidad de esta situación sólo al gobierno. El Congreso la tiene y grande por sus inagotables iniciativas para aumentar empleos y remuneraciones y el despacho de suplementos para gastos establecidos por ley". Boletín mensual de la Sociedad de Fomento Fabril (enero 1936), p. 39.

24 Por ejemplo: Ibáñez Santa María, "Los ingenieros, la política y la política en Chile”, op. cit.; Ibáñez Santa María, "El liderazgo de los gremios empresariales", op. cit.

25 Villalobos, Sergio y Sagredo, Rafael, El proteccionismo económico en Cbile. Siglo XIX, Santiago, Instituto Blas Cañas, 1987.

26 Boletín mensual de la Sociedad de Fomento Fabril (abril 1934), p. 40.

27 Boletín mensual de la Sociedad de Fomento Fabril (junio 1934), p. 298.

28 Boletín mensual de la Sociedad de Fomento Fabril (junio 1934), p. 319. 
Ortega, en una publicación reciente, sostiene que "a lo largo de esta etapa [1925-1975], el empresariado industrial adhirió, desde una posición de vulnerabilidad resultante de los estragos causados por el crack de 1929-1933, y sin una propuesta estratégica propia, al proyecto oficial respecto del fomento de la producción industrial" 29 . Sin embargo, la revisión de la prensa empresarial de los años post-crisis, y su impacto en el diseño de las políticas de fomento tanto del periodo 1933-1938 como del 1939-1954, ponen seriamente en duda esta interpretación.

\section{La Corfo, el Frente Popular y la consolidación del proyecto del Consejo de Economía Nacional}

La consolidación de las ideas que dieron forma al proyecto empresarial del Consejo de Economía Nacional, tuvo lugar en el contexto de un periodo de gobiernos de centro-izquierda (1938-1952), los que intentaron implementar un programa político-económico diametralmente opuesto al de la CPC, al menos en el plano político-ideológico. El programa del Frente Popular, en lo referente a la política-económica, estaba basado en cinco puntos. Primero, el aumento de la producción y la redistribución de la riqueza. Segundo, la supresión de monopolios y la defensa del patrimonio nacional, amenazado por empresas imperialistas extranjeras. Tercero, la revisión crítica de la deuda externa, para enfocar sus usos en los intereses de la clase trabajadora. Cuarto, la reforma agraria, basada en el apoyo a pequeños-medianos agricultores. Quinto, el establecimiento de políticas anti-inflación conducentes a mejorar la calidad de vida de los asalariados. ${ }^{30}$

Si bien la reforma agraria y la sindicalización campesina - como aseveran varios autores ${ }^{31}$ - no

pudo llevarse a cabo debido a presiones o acuerdos políticos, el resto del programa fue puesto en marcha sin demasiadas alteraciones. En este apartado se intenta explicar la forma en que el proyecto político empresarial de la CPC logra ser implementado a pesar de convivir con un programa de centro-izquierda. Con este propósito, hemos propuesto que, para llevar a cabo un análisis crítico en torno al Estado desarrollista, es necesario diferenciar con precisión administración estatal de financiamiento estatal.

En lo que se refiere al financiamiento, el carácter estatal de la Corfo no da lugar a dudas. Se dio preferencia al uso de recursos públicos, y se dejaron de utilizar los préstamos del Banco Central - que fueron la base del modelo de fomento en el periodo 1933-1938 - por sus consecuencias inflacionistas. Además, se eludieron las cargas tributarias excesivas al empresariado nacional, prefiriendo los impuestos a las ganancias de las empresas extranjeras extractoras de cobre y a los créditos externos. Con esto se intentaba seguir los lineamientos anti-imperialistas del programa del Frente Popular, sin afectar demasiado los intereses del empresariado local. En 1942, por ejemplo, los recursos del programa nacional de fomento provenían de: impuestos a compañías cupríferas foráneas (34\%), créditos externos (29\%), impuestos a la renta $(23 \%)$, préstamos de la banca nacional $(12 \%)$ y deudores morosos $(2 \%) .{ }^{32}$ Junto con esto, se le conceden a la Corporación otro sinnúmero de atribuciones indirectas de recursos públicos, como los montos anteriormente destinados al pago de la deuda externa (suspendida transitoriamente en 1939), la totalidad de la moneda extranjera obtenida de los impuestos y la posibilidad de solicitar

\footnotetext{
29 Ortega, Luis, "La economía política de la industrialización a través de un siglo" en Jaksic, Iván; Estefane, Andrés; Robles, Claudio (eds.), Historia política de Chile, 1801-2010. Tomo III: problemas económicos, Chile, FCE Chile, 2018, p. 159.

30 Garcés, Movimiento obrero, op. cit., pp. 219-222.

31 Por ejemplo: Joselyn-Holt, Alfedro, Correa, Sofía; Figueroa, Consuelo; Rolle, Claudio; y Vicuña, Manuel, Historia del siglo XX chileno, Santiago, Editorial Sudamericana, 2001; Arriagada, Ana María y Muñoz, Oscar, Los orígenes políticos y económicos del estado empresarial en Chile, Chile, CIEPLAN, 1977, p.145; 24-38; Ortega, Luis, Corfo: cincuenta años de labor, Santiago, Corfo, 1990, pp. 5556.

32 Corfo, Cinco años de labor. Santiago, Corfo, 1944, p. 68.
} 
préstamos en el mercado financiero internacional de manera autónoma, pero con garantía estatal. ${ }^{33}$ Desde 1948, el aporte fiscal a la Corporación pasa a ser un ítem del gasto general del fisco. ${ }^{34}$

En el campo de la administración, sin embargo, el carácter estatal de la Corporación es más ambiguo. En los debates en torno al proyecto que crea la Corfo, a inicios de 1939, diversos actores desde sectores políticos totalmente distintos - coincidieron al considerar que la Corporación significaba una pérdida de capacidad de acción tanto para el poder ejecutivo como para el legislativo.

Para los políticos de oposición - en especial, para los del partido conservador - el proyecto que creaba la Corfo era cuestionable e incluso anti-constitucional, pues implicaba la aprobación de cuantiosos recursos públicos, para la implementación de un programa nacional de fomento que, antes de la votación, no había sido formulado. Ciertas voces de la oposición afirmaron que era "absurdo y contrario al simple sentido común contratar enormes empréstitos para desarrollar un plan de fomento que no se conoce, un plan de fomento que se va a empezar a estudiar por la Corporación que crea esta ley". ${ }^{35}$ Según los parlamentarios, "el congreso va a entregar la distribución de mil millones de pesos sin saber en qué objetos van a ser invertidos, lo que es inconstitucional o inaceptable". ${ }^{36}$ No era recomendable entonces que "se le concedan facultades que la Constitución otorga privativamente al Senado, o más ampliamente, al Poder legislativo" 37.

Los parlamentarios oficialistas (socialistas, comunistas y radicales) coincidieron en el diagnóstico de los conservadores: el proyecto que creaba la Corfo otorgaba funciones administrativas a actores noestatales. No obstante, esto era un mal menor, necesario para poder consensuar un plan nacional de fomento basado en el equilibrio entre distintos poderes. La Corfo estaba pensada como un organismo corporativo multi-gremial, cuya gestión estuviera al mando de los ministros de Estado, las cámaras del parlamento, los gremios empresariales, los institutos técnico-científicos y los sindicatos. El principal argumento esgrimido por el gobierno era que, el aumento de la producción y el fomento al sector empresarial, terminaba, inevitablemente, por mejorar las condiciones de vida de la clase trabajadora. ${ }^{38}$ Con respecto a este punto, Roberto Wachholtz, ministro de hacienda encargado de presentar el proyecto, aseveraba:

Creo que todos estamos de acuerdo en la urgencia de mejorar las condiciones de vida de nuestro pueblo, y ello constituye uno de los fines principales, cuando no el más importante del plan de fomento de la producción [...] Pero reconociendo estas justas aspiraciones y la legitimidad de los medios empleados para lograrlas, es evidente, también, que el ejercicio de estas actividades tiene que realizarse de modo que no cause perturbaciones a la producción, pues cualquier trastorno de esta repercute fatalmente en toda la población y en especial en aquellos quienes más se desea favorecer con las medidas de fomento ${ }^{39}$

\footnotetext{
33 Bulnes, Luis, La corporación de fomento de la producción, Santiago, 1943, p. 245; Fermandois, Joaquín, Fragmentos acerca del fin del mundo. Artículos y ensayos sobre Chile, Santiago, Centro de Estudios Bicentenario, 2015, p. 242.

34 Corfo, Diez años de labor, Santiago, Corfo, 1950, p. 14; Ortega, op. cit., p. 109.

35 CNCh: Cámara de senadores: BSE 1938-1939, 28 de marzo de 1939, p. 476.

36 CNCh: Cámara de senadores: BSE 1938-1939, 29 de marzo de 1939, p. 511.

${ }^{37}$ CNCh: Cámara de senadores: BSE 1938-1939, 29 de marzo de 1939, p. 489.

38 Ciertos historiadores coinciden en este aspecto. Por ejemplo: Para Muñoz y Arriagada: "En el plano propiamente económico, el Gobierno pretende impulsar un nuevo modelo de desarrollo. Este objetivo se ve fuertemente influido, por una parte, por la conciencia de una dependencia externa que caracterizaba a la economía chilena y que la sometía periódicamente a importantes desequilibrios de origen exterior; y por otra, por la necesidad de enfrentar estructuralmente los problemas relacionados con el bajo nivel de vida de la población, especialmente de las masas trabajadoras". Arriagada y Muñoz, Orígenes políticos y económicos del estado empresarial en Chile, op. cit., p. 24. Fermandois, de la misma manera, considera que: "El programa original de la Corfo era resultado de las ideas escritas por un ingeniero, Desiderio García Ahumada, a cargo de la entonces Subsecretaría de Comercio Exterior de la Cancillería, trabajo hecho para la candidatura de Ross. El plan fue adaptado por las nuevas autoridades [...] No se trataba sólo de una política del Frente Popular, o de izquierda, o centro-izquierda. El sector empresarial había apoyado de manera decidida esta política. Fermandois, Mundo y fin de mundo, p. 173.

39 CNCh: Cámara de senadores: BSE 1938-1939, 28 de marzo de 1939, p. 512.
} 
El mismo argumento fue utilizado por Oscar Schnake, líder del partido socialista y ministro de fomento (1939-1941). Schnake consideraba el aumento de la producción como una instancia de conciliación entre clases sociales antagónicas:

Para mejorar de situación, necesitamos aumentar la producción, es decir, necesitamos hacer un mayor trabajo, necesitamos hacer producir más tierra, explotar más nuestros minerales y poner en mayor movimiento las fábricas, establecer industrias, y perfeccionar las existentes.

No podrán mejorar nuestras condiciones económicas personales o familiares, si nos lanzáramos al reparto de la poca riqueza que el país produce [...] Todos comprenden que, para vivir mejor, es necesario producir más, para que así tengamos más riquezas de qué disfrutar. Chile presenta en sus sindicatos, un fenómeno que lo debe llenar de orgullo, y es el de una conciencia de interés colectivo, una gran conciencia nacional.

Estos dos tipos de hombres: nuestro trabajador, lleno de una nueva conciencia, y el patrón o el jefe de industria, que también tiene esta nueva conciencia, son dos pilares sólidos para que el país pueda proseguir su curso de adelanto progresivo ${ }^{40}$

Los gremios empresariales coincidieron con los parlamentarios, pero siguieron reiterando lo inconveniente que podría llegar a ser la excesiva incidencia del poder ejecutivo en la administración de la corporación. La reducción de la intervención gubernamental directa era - como fue formulado en 19361938 en el proyecto del Consejo de Economía Nacional - condición necesaria para la correcta gestión de los fondos públicos. Las corporaciones como la Corfo debían ser concebidas como:

una garantía de competencia en el manejo de los fondos públicos y que ofrezcan la seguridad de un predominio de ideas económicas sobre las de carácter político. La certidumbre de que se realice lo último la proporciona desde luego la reducción de la representación fiscal y el aumento de la perteneciente a las entidades productoras y comerciales ${ }^{41}$

Lo importante era reducir la capacidad de acción de las fuerzas políticas, motivadas supuestamente por ideologías políticas y no por criterios técnicos o económicos: "la mayor representación industrial, comercial y agrícola sobre la fiscal, afianzará el predominio económico sobre cualquiera otro de carácter político" 42 . El programa nacional no podría llevarse a cabo "en forma práctica y expedita si no deriva de un organismo en el cual se emitan libremente las opiniones y se promueva una acción de cabal entendimiento de la situación". ${ }^{43}$ No obstante, a pesar de estas recomendaciones, los círculos empresariales intentaron "no obstaculizar el plan de fomento a la producción, ya que, en cierto modo, la Corporación equivalía al Consejo de Economía Nacional". ${ }^{44}$ Para la Sofofa, al fin y al cabo, las atribuciones de los representantes patronales en la Corporación eran "amplias y categóricas" 45.

Ahora bien, las disposiciones legales no fueron el único mecanismo con el que los círculos empresariales consiguieron reducir la incidencia de los agentes gubernamentales en la administración de los fondos públicos. Existieron un sinnúmero de redes indirectas que ponen en cuestión el supuesto equilibrio de poderes tanto de la Corfo como del resto de los organismos estatales encargados de la política económica, como los institutos-semifiscales de fomento o el Banco Central. Con frecuencia, los ministros - que supuestamente debían representar los intereses del gobierno de turno en estas entidades - eran miembros de gremios empresariales o mantenían vínculos con compañías beneficiadas financieramente

40 Oscar Schnke en Partido Socialista de Chile: Política económica del Frente Popular. Santiago 1941, p. 19, p. 16, p. 15.

41 CPC: La Confederación (marzo 1939), p. 83.

42 Sofofa: Boletín mensual (marzo 1939), p. 148.

43 CPC: La Confederación (marzo 1939), p. 82.

44 Ortega, Corfo: cincuenta años, op. cit., p. 55.

45 Sofofa: Boletín mensual (abril 1939), p. 221. 
por el Estado. En el periodo 1938-1945, por ejemplo, tres ministros de hacienda, cuatro ministros de agricultura y dos ministros de economía y comercio fueron miembros de gremios empresariales como la Sofofa o la CPC. 46

Cuadro 2. Vinculaciones de directores de la Corfo con asociaciones empresariales o el sector privado o público/privado 1939-1944

\begin{tabular}{|c|c|c|}
\hline & $\begin{array}{l}\text { Asociaciones } \\
\text { empresariales }\end{array}$ & Relación con el sector privado o público/privado \\
\hline $\begin{array}{l}\text { Ricardo Letelier } \quad \text { Ruiz } \\
\text { (vicepresidente) }\end{array}$ & & $\begin{array}{l}\text { Gerente del Banco de Chile, Director de Corporación Radio Chile } \\
\text { S.A., de Saavedra Bernar S.A.C., de la Soc. General de Comercio, } \\
\text { de Soc. El Tattersall, de Industria Nac. De Neumáticos, S.A., }\end{array}$ \\
\hline $\begin{array}{l}\text { Guillermo Del Pedregal } \\
\text { (vicepresidente) }\end{array}$ & $\begin{array}{l}\text { Consejero de la } \\
\text { CPC }\end{array}$ & $\begin{array}{l}\text { Presidente de Asociación de Aseguradores de vida, presidente de la } \\
\text { Empresa Nacional de Transporte Colectivo, presidente de Soc. } \\
\text { Pesquera Arauco, presidente Soc. de Productos Patria. }\end{array}$ \\
\hline Oscar Gajardo (vicepresidente) & & $\begin{array}{l}\text { Presidente de Industria Nacional de Neumáticos, director de } \\
\text { Sedyland S.A.C. }\end{array}$ \\
\hline $\begin{array}{lll}\text { Gustavo } & \text { Rivera } & \text { (PL) } \\
\text { (representante del senado) } & \end{array}$ & & $\begin{array}{l}\text { Abogado de firmas Lea, Pudeusan y Cía., Enrique Oerthy, Balfour } \\
\text { Lyon y Cía., Asoc. Canal del Maule. Director de Cía de Electricidad. } \\
\text { Presidente de Cía. Carbonera Victoria de Lebu. Director de } \\
\text { Consorcio chileno-peruano. }\end{array}$ \\
\hline $\begin{array}{lcc}\text { Carlos } & \text { Martínez } & \text { (PS) } \\
\text { (representante del senado) }\end{array}$ & & \\
\hline $\begin{array}{l}\text { Carlos Gaete (PS) (representante } \\
\text { diputados) }\end{array}$ & & Director de Consorcio Nacional de Aves \\
\hline $\begin{array}{lll}\text { Gustavo } & \text { Loyola } & \text { (Con) } \\
\text { (representante diputados) }\end{array}$ & & Arquitecto de Cía. Carbonifera de Lebu \\
\hline $\begin{array}{l}\text { Victor Moller (PR) (presidente } \\
\text { CCH) }\end{array}$ & SNA & \\
\hline $\begin{array}{l}\begin{array}{l}\text { Alfonso } \\
\text { (vicepresidente del IEG) }\end{array} \\
\end{array}$ & & Presidente de Vinos Chile S.A. \\
\hline $\begin{array}{l}\text { Francisco Solar (vicepresidente } \\
\text { del CNCE) }\end{array}$ & & Consejero de L.A.N. \\
\hline $\begin{array}{l}\text { Alberto Gómez (representante } \\
\text { del ICI) }\end{array}$ & & $\begin{array}{l}\text { Consejero de Cía. Siderúrgica e Industrial de Valdivia. Director } \\
\text { General de Crédito Prendario y Casas de Martillo }\end{array}$ \\
\hline $\begin{array}{lll}\text { César } & \text { Fuenzalida } & (\mathrm{PR}) \\
\text { (representante de la CCM) } & \end{array}$ & $\begin{array}{l}\text { Consejero de la } \\
\text { CPC }\end{array}$ & $\begin{array}{l}\text { Director General de Crédito Popular y Casas de Martillo. Gerente } \\
\text { de Cía. de Electricidad Industrial. Consejero Soc. Abastecedora de } \\
\text { Minería. Director de Cía. Electro Siderúrgica de Valdivia, S.A., }\end{array}$ \\
\hline \multicolumn{3}{|l|}{$\begin{array}{l}\text { Enrique Morel (representante de } \\
\text { la CCA) }\end{array}$} \\
\hline $\begin{array}{l}\text { Joaquín } \\
\text { (representante de la SNA) }\end{array}$ & $\begin{array}{l}\text { Presidente de la } \\
\text { SNA }\end{array}$ & $\begin{array}{l}\text { Director de la central de Leche, presidente de Cooperativa Lechera } \\
\text { Santiago }\end{array}$ \\
\hline $\begin{array}{l}\text { Walter Muller (representante de la } \\
\text { Sofofa) }\end{array}$ & $\begin{array}{l}\text { Sofofa, Sonami, } \\
\text { SNA y CPC }\end{array}$ & $\begin{array}{l}\text { Gerente Cía. de Consumidores de Gas de Santiago; presidente de } \\
\text { Cía. Chilena de Fósforos; Director de Fábrica de Loza Nacional de } \\
\text { Penco; Gerente General de Cía. Electro Siderúrgica de Valdivia S.A; } \\
\text { Dirigente de Cía. de Petróleos de Chile, director de Cía. de } \\
\text { Teléfonos de Chile; director de Nieto y Cía., director de Soc. Clínica } \\
\text { Alemana, Director de Corp. de Radio de Chile }\end{array}$ \\
\hline $\begin{array}{l}\text { Osvaldo Martínez (representante } \\
\text { de la Sonami) }\end{array}$ & $\begin{array}{l}\text { Presidente de la } \\
\text { Sonami }\end{array}$ & \\
\hline $\begin{array}{l}\text { Gastón de Goyeneche } \\
\text { (representante de la CChC) }\end{array}$ & & $\begin{array}{l}\text { Propietario de Botica Francia (Santiago), Fundador de Laboratorio } \\
\text { Francia, Fundador y Presidente de Laboratorio Geka, presidente y } \\
\text { Gerente de Cons. De Comercio Exterior S.A., consejero de Cía. }\end{array}$ \\
\hline
\end{tabular}

${ }^{46}$ Casanova, Mauricio, Los origenes del desarrollismo económico en Chile, Berlín, Universidad Libre de Berlín (Tesis doctoral), 2018, pp. 173-176. 


\begin{tabular}{|c|c|c|}
\hline & & $\begin{array}{l}\text { Chilena de Electricidad, director del Banco de Créditos e } \\
\text { Inversiones, }\end{array}$ \\
\hline $\begin{array}{l}\text { José Luis Claro (representante del } \\
\text { IICh) }\end{array}$ & & $\begin{array}{l}\text { Ingeniero de Cía. General de Electricidad Industrial, Gerente de } \\
\text { Soc. Lechera de Miraflores, presidente de Cía. Minera de Punitaqui, } \\
\text { director de Soc. Anónima. Cemento Juan Soldado Consolidada de } \\
\text { Valparaíso }\end{array}$ \\
\hline \multicolumn{3}{|l|}{$\begin{array}{l}\text { Raul Morales (PR) (representante } \\
\text { del presidente) }\end{array}$} \\
\hline $\begin{array}{l}\text { Benjamín Matte (representante } \\
\text { del presidente) }\end{array}$ & $\begin{array}{l}\text { Presidente de la } \\
\text { SNA }\end{array}$ & $\begin{array}{l}\text { Presidente de la Unión Lechera de Aconcagua, presidente del } \\
\text { Consorcio Nacional de Productores de Aves }\end{array}$ \\
\hline $\begin{array}{l}\text { Enrique Mozó (representante del } \\
\text { presidente) }\end{array}$ & & $\begin{array}{l}\text { Presidente Ejecutivo de Sociedad Maderera del Sur, Gerente de } \\
\text { Casa Bayer. }\end{array}$ \\
\hline $\begin{array}{l}\text { Néstor Valenzuela (PL) } \\
\text { (representante del presidente) }\end{array}$ & & $\begin{array}{l}\text { Sub gerente del Banco Régulo Valenzuela, Vicepresidente de } \\
\text { Consorcio Comercial Chileno Peruano y Consorcio Mercantil de } \\
\text { Santiago, vicepresidente de S.A. Régulo Valenzuela, Director de } \\
\text { Ingeniería Eléctrica S.A.C., director de Cía. Sueco Chilena, director } \\
\text { de Soc. A la Ville de Nice, director de Soc. PhilcoChile, director de } \\
\text { Soc. Técnica Errázuriz y Cía. }\end{array}$ \\
\hline \multicolumn{3}{|l|}{$\begin{array}{l}\text { Jorge Rogers (FN) (representante } \\
\text { del presidente) }\end{array}$} \\
\hline $\begin{array}{l}\text { Nicasio Retamales (representante } \\
\text { del presidente) }\end{array}$ & & $\begin{array}{l}\text { Fundición Libertad de Santiago, vicepresidente de la Cía. } \\
\text { Siderúrgica de Valdivia }\end{array}$ \\
\hline \multicolumn{3}{|l|}{$\begin{array}{l}\text { Desiderio García } \quad \text { (gerente } \\
\text { general) }\end{array}$} \\
\hline $\begin{array}{l}\text { Emiliano Bustos } \quad \text { (gerente } \\
\text { administrativo) }\end{array}$ & & $\begin{array}{l}\text { Presidente de la Soc. Industrial Pesquera de Tarapacá S.A., } \\
\text { Vicepresidente de Vinos de Chile S.A. }\end{array}$ \\
\hline Laín Diez (depto. de minería) & & Ingeniero del depto. técnico de firma Siemens-Schuckert Ltda. \\
\hline \multicolumn{3}{|l|}{ Javier Olea (depto. de agricultura) } \\
\hline $\begin{array}{l}\text { Gustavo Vicuña (depto. de } \\
\text { industrias) }\end{array}$ & & Director de Soc. Industrial Pesquera de Tarapacá \\
\hline $\begin{array}{l}\text { Guillermo Moore (depto. de } \\
\text { energía) }\end{array}$ & SNA & \\
\hline \multicolumn{3}{|l|}{$\begin{array}{l}\text { Francisco Steeger (departamento } \\
\text { de comercio) }\end{array}$} \\
\hline \multicolumn{3}{|l|}{$\begin{array}{l}\text { Emiliano Alvarado (depto. de } \\
\text { contabilidad) }\end{array}$} \\
\hline $\begin{array}{l}\text { Jorge Wenderoth (depto. de } \\
\text { control) }\end{array}$ & & \\
\hline
\end{tabular}

Fuente: Empresa Periodística de Chile, Diccionario Bibliográfico de Chile, Santiago. Años utilizados: 1939, 1940, 1941, 1942, 193, 1944, 1945, 1947, 1948. Las abreviaciones utilizadas son las siguientes: Sofofa (Sociedad de Fomento Fabril); Sonami (Sociedad Nacional de Minería), SNA (Sociedad Nacional de Agricultura); CPC (Confederación de la Producción y el Comercio), CChc (Cámara Chilena de Comercio); ICI (Instituto de Crédito Industrial); CCA (Caja de Crédito Agrario); CCM (Caja de Crédito Minero); CCH (Caja de Crédito Hipotecario); IEG (Instituto de Economía Agrícola); CNCE (Consejo Nacional de Comercio Exterior); IICh (Instituto de Ingenieros de Chile).

Como es posible observar en el Cuadro 2, estas redes indirectas también se manifestaron en los miembros de la Corfo. Si bien los vínculos de los delegados de los gremios empresariales (Sofofa, CPC, SNA, Sonami, etc.) en la Corporación con el sector privado son obvios o esperables, llama la atención los vínculos de los actores que supuestamente debían representar los intereses del gobierno. Si se observa el cargo representante del presidente, es posible observar que solamente un miembro forma parte de asociaciones empresariales - Benjamín Matte (presidente de la SNA) - pero que la gran mayoría posee vínculos con empresas. El caso de Néstor Valenzuela, por ejemplo, perteneciente al Partido Liberal, es el más ilustrativo: era, por un lado, representante del ejecutivo, y, por otro, asociado de varias compañías 
comerciales y financieras. Una situación similar sucedía con los representantes del poder legislativo. Incluso dirigentes socialistas, como el diputado Carlos Gaete, tenían algún vínculo con el sector empresarial.

En el Cuadro, en la última parte, se puede apreciar un conjunto de delegados de la Corporación, como el Gerente General o los jefes de los departamentos de agricultura, comercio o transportes, que no poseían mayores vínculos ni con gremios empresariales ni con el mundo empresarial. Estos actores corresponden a lo que ciertos autores denominan clase técnico-burocrática, la que supuestamente habría sido protagonista en la gestión del Estado desarrollista ${ }^{47}$. Cavarozi, por ejemplo, sostiene que "durante el periodo de los gobiernos radicales, la junta directiva de la institución tuvo una participación limitada en las decisiones políticas de la Corfo, y virtualmente ninguna influencia ni en el diseño de planes sectoriales ni en la selección de los proyectos que debían ser apoyados". ${ }^{8}$ Silva, igualmente, asegura que, en la gestión del Estado empresario, destaca "un grupo estratégico específico de ingenieros, los que, desde fines de la década de 1920 hasta mediados de la de 1950, jugaron un rol clave en la formulación e implementación de las politicas estatales de industrialización". ${ }^{49}$ Si bien este componente técnico - que no pertenece ni a la oligarquía tradicional ni a las organizaciones obreras - está presente, no se puede negar la evidente presencia de los intereses empresariales no solamente en la Corfo, sino también en el resto de entidades encargadas de la administración de fondos públicos o de la ejecución de políticas-económicas ${ }^{50}$ (como el Banco Central, por ejemplo ${ }^{51}$ ).

Además, la gestión técnico-burocrática del Estado empresario era una demanda histórica de los mismos gremios empresariales ${ }^{52}$, basada en la idea que las políticas de fomento no debiesen depender ni del poder ejecutivo ni del legislativo. La presencia de esta burocracia estatal, por tanto, no puede concebirse como un proceso contrario a los intereses de los gremios empresariales. Fueron estos actores los que propusieron inicialmente la tecnificación del Estado. Antes del poder de la burocracia-técnica, estuvo el poder empresarial, que propuso la tecnificación de la burocracia como parte de una propuesta política basada en la administración no-estatal de los recursos estatales. Por este motivo, como se examina en la próxima sección, las instancias en donde el poder ejecutivo tuvo realmente algún espacio de acción (como las políticas sociales), estuvieron caracterizadas por el continuo des-financiamiento.

47 Cavarozzi, Marcelo, The government and the industrial bourgeoisie in Chile: 1938-1964, Berkeley, University of California (Tesis doctoral), 1975; Silva, Silva, In the name of reasons: technocrats and politics in Chile, Philadelphia, The Pennsylvania State University Press, 2009; Pinto, Julio y Salazar, Gabriel, Historia contemporánea de Chile III. La economía: mercados, empresarios y trabajadores, Santiago, LOM, 2002, pp. 76-84.

48 Cavarozzi: The government, p. 123. Traducción del autor. Texto original: "during the period of the Radical Regimes, the institution's Board of Directors had a very limited participation in the making of CORFO's policies, and virtually no influence upon the choices made in drawing sectorial plans and selecting projects to be supported"

49 Silva: In the name of reason, p. 86. Traducción del autor. Texto original: "Within the techno-structure a specific strategic group of engineers can be identified who, from the late 1920s to the mid-1950s, played a key role in the formulation and implementation of the state industrial policies".

50 "Se puede señalar que hasta 1964, las asociaciones empresariales eran el grupo de presión más poderoso del país; sus enormes recursos, sus conexiones con los parlamentarios, la representación en el aparato estatal y en las empresas públicas, aseguraron su influencia en los procesos de toma de decisiones políticas". Rubio, Pablo y Salgado, Xaviera, "Gremios empresariales y derecha chilena: redes de poder y propuestas programáticas de la Sociedad Nacional de Agricultura, 1952-1958”, Amérique Latine Histoire et Mémoire, número 32, 2016. "Los grupos de poder del centro; agricultores, ganaderos, industriales, comerciantes e importadores, estrechamente vinculados por lazos familiares y económicos, a través de los partidos Conservador y Liberal mantuvieron una importante presencia en el sistema político multipartidista nacional y en el Estado, incluso durante los Gobiernos de centro-izquierda del período 1938-1952, consolidando y protegiendo la centralización política y económica del país". Alminacid, Claudio, La agricultura chilena discriminada (1910-1960): Una mirada de las políticas estatales y el desarrollo sectorial desde el sur, Santiago, Editoria CSIC, 2016.

51 Para un análisis más detallado sobre las redes empresariales indirectas en los delegados del gobierno en el Banco Central, véase: Casanova, op. cit., pp. 217-219.

52 Ibáñez Santa María, “Los ingenieros, la política y la política en Chile”, op. cit.; Ibáñez Santa María, "El liderazgo de los gremios empresariales”, op. cit. 
Otro argumento utilizado comúnmente por historiadores, es que el protagonismo del Estado en la economía se reflejaría en la fundación de empresas estatales en sectores claves, como la Compañía de Acero del Pacífico (CAP), la Empresa Nacional de Electricidad (ENDESA) o la Empresa Nacional del Petróleo (ENAP). Sin embargo, no se menciona con frecuencia que, si bien tanto CAP como ENDESA surgieron como proyectos de empresas administradas y financiadas por el Estado, estas terminaron por convertirse en sociedades anónimas, debido a la oposición de la misma Corfo. El carácter de persona jurídica de derecho privado "reforzaba la actitud de la Corporación de velar celosamente por su autonomía técnica frente al sector estatal tradicional, al cual veía demasiado contaminado por influencias partidistas". ${ }^{53}$ En los delegados presidenciales nombrados para el directorio de estas empresas, las redes indirectas del mundo empresarial se manifestaban de igual manera que en la Corfo. El financiamiento estatal, en estas empresas, y en la mayoría de las compañías público/privadas, no significaba que el Estado tuviera un rol relevante en la administración. Hasta el mismo presidente de la república llegó a defender esta postura:

La atenta lectura que ha hecho de la carta de S.E. [Juan Antonio Ríos, presidente de la república (19421946)], y su contexto lógico, me ha convencido de que S.E. resuelve esta vieja cuestión, que es la más importante, a mi juicio, de las que ha preocupado a este interesante organismo, en el sentido primero, esto es que la Corporación debe hacer su ayuda a los productores solo por medio de préstamos, sin que el capital estatal alcance condiciones de codueño de la industria ${ }^{54}$

Según Guajardo Soto, existen tres modelos de Empresas públicas: “1) sección o agencia dentro de un ministerio o secretaría; 2) entidad legal separada del gobierno, pero denominada empresa o corporación pública; 3) participación del Estado en el paquete accionario [...] en un gran número de entidades". ${ }^{55} \mathrm{El}$ modelo base de la Corfo era claramente el segundo, y su accionar cercano al modelo tercero, pues - al menos en estos primeros años - los gastos estuvieron focalizados en rubros como la compra de acciones a sociedades empresariales o los créditos directos a empresas. ${ }^{56}$ Era lo que Meller denomina como "Estado-promotor, que proporcionaba el crédito para la inversión privada". ${ }^{57}$

En síntesis, el Estado empresario estaba financiado estatalmente, pero no administrado plenamente - por agentes del Estado (poderes ejecutivo/legislativo). Ciertos autores, como Montero, han caracterizado este modelo como estilo empresarial corporativ $0^{58}$, basado en la cooperación entre el sector público y el privado. No obstante, el examen de las propuestas empresariales del periodo 1936-1938, de las discusiones en torno a la creación de la Corfo o de la presencia indirecta de los intereses empresariales en los representantes estatales, ponen en cuestión esta conceptualización. Lo novedoso del periodo desarrollista post-1939, no es tanto la formación del Estado empresarial - cuyos orígenes pueden datarse incluso hasta inicios del siglo XX ${ }^{59}$ - sino la consolidación de un modelo sustentado en la administración

53 Endesa, Cincuenta años, Santiago 1993, p. 37.

${ }^{54}$ Rogers, Jorge, La Corporación de Fomento y la economía del futuro. Exposición leída en el consejo de la Corporación del día 25 de septiembre de 1944. Santiago 1945, p. 12

55 Guajardo Soto, Guillermo, "Las empresas públicas chilenas: una historia de diversidad, crisis y continuidad, 1811-2010" en Jaksic, Iván; Estefane, Andrés; Robles, Claudio (eds.), Historia política de Chile, op. cit. P. 318.

56 Corfo, Cinco años, op. cit., pp. 74-77.

57 Meller, Patricio, Un siglo de economía política chilena 1890-1990. Santiago, Editorial UAB, 1998, p. 59.

58 Montero, La revolución empresarial chilena, op. cit.

59 "El estatismo insinuado por Ibáñez y retomado por los gobiernos posteriores a la crisis de 1930, incluyendo el bastante conservador del «segundo» Arturo Alessandri Palma, no hizo sino profundizar ciertas líneas de intervención que venían de más atrás", Salazar y Pinto, op. cit., p. 79; "Se ha menospreciado la relación del Estado chileno con la economía a principios del siglo $\mathrm{XX}$, cuando los datos demuestran que fijaba la política monetaria y emitía los decretos claves sobre la reconversión. Fue el promotor de las obras de infraestructura de caminos, puentes, ferrocarriles y telecomunicaciones. Intervino en el régimen salarial y la dictación de leyes sociales. Fijaba los porcentajes en los derechos de exportación de las materias primas, percibía la renta 
no-estatal de los recursos estatales. Esta fue la principal razón por la cual el plan de la CPC y el proyecto del Consejo de Economía Nacional pudo ser implementado, a pesar de convivir con un gobierno de centroizquierda. Como manifestó la CPC en 1936-1938, el problema no era ni la izquierda ni la derecha, ni Alessandri ni Aguirre Cerda, sino los poderes ejecutivo y legislativo. Según Moulian, los gobiernos de centro-izquierda "debieron limitarse a un programa de desarrollo capitalista, sustituyendo en las tareas de modernización a los grupos propiamente burgueses" ${ }^{0}$. Sin embargo, parecen haber sido los grupos propiamente burgueses los que en la práctica terminaron sustituyendo a los gobiernos de centro-izquierda en las tareas de modernización.

\section{De la financiación del Estado empresario a la des-financiación del Estado social 1938-1954}

El Estado social había comenzado a forjarse en los inicios del siglo XX. Primero con las leyes de habitaciones obreras (1906), la ley de descanso semanal (1907) y la oficina del trabajo (1907). Luego, con la creación de la Dirección General del Trabajo (1924), el Ministerio de Bienestar Social (1924-1932), la Caja de Seguro Obrero (1924) y el Ministerio del Trabajo y Seguridad social (desde 1932). El Código del Trabajo de 1931 representa la consolidación de este proceso inicial, en el que se logra institucionalizar tanto el conflicto laboral como la seguridad social. Además, en el segundo gobierno de Alessandri se aprueba la ley de salario mínimo para los empleados del comercio y la industria (1934) y se crea la Caja de Habitación Popular (1936). Sin embargo, como se sostiene en un estudio reciente, "fue a partir de la victoria del Frente Popular y la alianza formal entre Pedro Aguirre Cerda y la Confederación de Trabajadores de Chile, que el Estado asumió un claro compromiso social con el mundo del trabajo". ${ }^{61}$ Las medidas más emblemáticas del periodo fueron implementadas a comienzos de la década de 1950: el Servicio Nacional de Salud (1952), el Servicio de Seguro Social (1953) y la Junta Nacional de Auxilio Escolar (1953).

Al igual que en el análisis del Estado empresario, la tesis del Estado de compromiso resulta inadecuada para examinar el desenvolvimiento del Estado social. Las políticas de asistencial social (salario, salud, educación, pensión, educación, seguridad laboral, etc.) del periodo 1938-1954 no fueron gestionadas por organismos corporativos, ni por instancias de cooperación entre gremios empresariales, agentes gubernamentales, parlamentarios, institutos técnico-científicos o sindicatos. En torno al Estado social, no hubo la conciencia nacional que - en palabras de Oscar Shnake - hubo con respecto al plan nacional de fomento. El Estado social estaba administrado casi en exclusividad por los gobiernos de centro-izquierda, los que tuvieron que enfrentar constantemente tanto el obstáculo de la derecha en el parlamento como la oposición de las voces empresariales. ${ }^{62}$

La estrategia de financiamiento también era diferente. Mediante distintos mecanismos legales, la mayor parte de los recursos provenientes de los tributos a las ganancias de las compañías cupríferas, así como también la moneda extranjera o la posibilidad de solicitar empréstitos externos, fueron reservados - en el periodo 1939-194863 - para los distintos programas de la Corfo. En consecuencia, las políticas

\footnotetext{
salitrera y redistribuía otros ingresos aduaneros. Era el único aval de los empréstitos contraídos con la banca internacional, además de dictar las leyes de inmigración”. Vitale, Luis, Interpretación marxista de la bistoria de Chile. España, Fontamara, 1980, p. 119 .

${ }^{60}$ Moulian, Tomás, "Desarrollo político y Estado de compromiso. Desajustes y crisis estatal en Chile", Colección de Estudios CIEPLAN, número 64, 1982, p. 109.

${ }^{61}$ Vergara Marshall, "Estado, trabajo y trabajadores", op. cit., p. 386.

${ }^{62}$ Correa, op. cit., pp. 71-81.

${ }^{63}$ Los aportes fiscales a la Corfo, mediante ítems específicos, dura hasta 1948. Dicho año, los aportes pasan a ser parte del gasto general de la nación. Corfo, Diezaños, op. cit., p. 17.
} 
sociales tuvieron que hacer uso de recursos a corto plazo; el Estado social, no era - como el empresario un "Estado-programador, que definía el horizonte de largo plazo del patrón chileno de desarrollo". ${ }^{64}$

A fines de 1951, la ley que reorganizaba los sueldos del sector público ${ }^{65}$, y que implicaba un aumento significativo de gastos, fue financiada mediante otra normativa ${ }^{66}$, en la que se extendía por un año la vigencia de diversos impuestos a la renta que habían sido fijados originalmente por un periodo de dos años. Esta estrategia de prórroga a corto plazo había comenzado en 194467 , y - mediante diversas leyes - se había extendido hasta 1951. Es decir, que - a inicios de 1952 - el aumento de salarios del sector público, en el que se incluía a los funcionarios de la salud o la educación, poseía financiamiento efectivo solamente hasta el 31 de diciembre de 1953.

A fines del 1952, la situación se vuelve a repetir. Se promulga otra ley para re-organizar los gastos del sector público ${ }^{68}$, en la que fueron incluidos los montos necesarios que faltaban para el cumplimiento de los pagos según lo establecían diversas leyes establecidas con anterioridad; incluida la de fines de 1951. Se vuelve entonces a extender la vigencia transitoria de los impuestos utilizados el año anterior. Además, se establecía otra serie de tributos menores a productos como, por ejemplo, las cervezas nacionales y la bencina; contradiciendo de esta manera las políticas proteccionistas e industrialistas del Estado empresario.

En otros casos, como en la creación del Fondo para la construcción y dotación de establecimientos de la Educación Pública ${ }^{69}$, se buscaba financiamiento no solo mediante el establecimiento de nuevos impuestos a la renta - como era frecuente - sino también mediante nuevos tributos a las pensiones de los jubilados o a los trabajadores obreros. Por tanto, en este caso, como en varios otros, las políticas sociales se contradecían entre sí. En consecuencia, cada año los gobiernos de centro-izquierda debían recurrir a la creación de nuevos tributos o a la estrategia de prórroga. Por este motivo, sobre todo en el periodo 19491954, ciertos años presupuestarios finalizaron con importantes déficits. Como sostiene Arellano, "no fue fácil imponer los costos y obtener el financiamiento de los nuevos programas. Esta apreciación se confirma al observar la complejidad del financiamiento de numerosos programas, para los cuales se creaban varios impuestos recaudados con ese fin específico"70. Este criterio cortoplacista "y la falta de claridad para enfrentar los problemas, condujo a que en la práctica las acciones sociales que se pretendía implementar en el área quedaran subordinadas a los desequilibrios macroeconómicos y terminaran por fracasar"71. Para Rengifo, "el sistema era costoso, deficitario, y demostró su incapacidad de pagar las prestaciones comprometidas, ni de garantizar el poder adquisitivo de las pensiones". ${ }^{72}$

Ante este escenario, los gobiernos se vieron forzados a utilizar un mecanismo de emergencia: los préstamos directos e indirectos del Banco Central. Es decir, que la estrategia de financiamiento al sector empresarial del periodo 1933-1938, desechada desde 1939 por los círculos empresariales debido a sus consecuencias inflacionistas, termina convirtiéndose en un recurso de última instancia para el Estado social. El Estado empresario, en el periodo 1939-1948, no solo tuvo la capacidad de reservarse los ingresos provenientes tanto del cobre como de los créditos externos, sino que también le cede al Estado social una estrategia de financiamiento rechazada, históricamente fracasada, y con graves efectos macroeconómicos.

64 Meller, op. cit., p. 59.

${ }^{65}$ DORCh, Ley 10.343 publicada el 17 de diciembre de 1951.

66 DORCh, Ley 10.257 publicada el 12 de febrero de 1952.

${ }^{67}$ DORCh, Ley 7.750 publicada el 7 de enero de 1944. Las leyes que extendieron sucesivamente el plazo de la ley 7.750 fueron las leyes 8. 404, 8.920 y 9.363 .

${ }_{68}$ DORCh, Ley 11.137 publicada el 27 de diciembre de 1952.

${ }^{69}$ DORCh, Ley 11.766 publicada el 30 de diciembre de 1954.

70 Arellano, José, Políticas sociales y desarrollo 1924-1984, Santiago, CIEPLAN, 1985, p. 42

71 Ministerio de Planificación y Cooperación, "Evolución de las políticas sociales en Chile 1921-1991”, Documentos sociales MIDEPLAN. 1991, p. 7.

72 Rengifo, "El estado de seguridad social”, op. cit., p. 399. 
Esta tendencia de recurrir a las emisiones del banco con fines presupuestarios comienza a adquirir notoriedad desde 1946. Desde aquel entonces, como sostuvo el banco, "el sector fiscal contribuyó a crear emisiones mediante la obtención de créditos directos en el Banco Central, e, indirectamente, a través de la colocación de valores en el instituto emisor y en la banca privada, destinados a financiar déficits presupuestarios". ${ }^{73}$ A fines de 1950, por ejemplo, se tuvo incluso que otorgar anticipos de sueldo a los funcionarios públicos mediante las emisiones provenientes de préstamos de la banca central. En 1955, el Banco llegó a sostener que "el presupuesto de ingresos fiscales era una clara expresión de la política expansiva del Estado, que intentaba años tras año, incrementar sus ingresos para financiar un volumen equivalente de gastos, en proporciones evidentemente exageradas". ${ }^{74}$

Como consecuencia de la continua utilización de este mecanismo de emergencia, la emisión de circulante del Banco Central para fines presupuestarios llega a convertirse en el periodo 1952-1954 en la principal causa de inflación: "La presión fiscal que se observa en este periodo fue de tal magnitud que las demás presiones inflacionistas decrecen en importancia, no obstante haber continuado en actividad" 75 . El alza del costo de la vida, en este contexto, comienza transformarse nuevamente en un problema que ha sido catalogado como desenfrenado, sistemático ${ }^{76}$ o progresivamente virulento ${ }^{77}$. Aníbal Pinto llegó a sostener que "la presencia y desarrollo de un proceso inflacionario de considerable persistencia e intensidad constituye, sin duda, uno de los perfiles dominantes de la evolución económica en el periodo que estamos examinando [1930-1953]. Para muchos, en realidad, ha significado el rasgo principal, que deja en la trastienda otros elementos característicos". 78

Finalmente, en 1955, el gobierno de Ibáñez decide recurrir a una asesoría estadounidense, la misión Klein \& Saks, para enfrentar esta situación. Los asesores consideraron, con acierto, que la crisis inflacionaria "tenía su origen en el déficit presupuestario que llevaba a emitir, y como esa emisión no estaba respaldada por un aumento correspondiente de la producción, se transformaba en alza de precios". ${ }^{79}$ Pero, para los delegados de la misión, habría sido el excesivo intervencionismo estatal, el que habría terminado por ofuscar el modelo de desarrollo. En esta investigación hemos intentado mostrar, en cambio, que el des-financiamiento del Estado social y la ausencia da una política nacional de cooperación - situación diametralmente opuesta a la conciencia nacional existente en el Estado empresario - fue lo que finalmente desencadena la crisis inflacionaria; y que este Estado social no era excesivamente intervencionista, sino débil y carente de programas. ${ }^{80}$

\footnotetext{
73 Memoria anual del Banco Central de Chile (1955), p. 57.

${ }^{74}$ Memoria anual del Banco Central de Chile (1955), p. 59.

${ }^{75}$ Memoria anual del Banco Central de Chile (1955), p. 64.

76 Ahumada, Jorge, En vez de la miseria, Santiago, Editorial del Pacífico, 1958, p. 15.

77 French-Davis, Ricardo y Muñoz, Oscar, "Desarrollo económico, inestabilidad, y desequilibrios políticos en Chile 1950-89", Colección de Estudios CIEPLAN, número 28, 1990, p. 123.

78 Pinto, Anibal, Chile, un caso de desarrollo frustrado, Santiago, Editorial Universitaria, 1973, p. 189.

79 Correa, Sofía, Con las riendas del poder, Santiago, Editorial Sudamericana, 2014, p. 201.

80 Según Correa Weffort, la idea de los organismos estatales como entidades independientes encargadas de llevar a cabo las iniciativas de diversos actores sociales-políticos constituye la esencia de la tesis del Estado de compromiso. Ahora bien, en la práctica, esta capacidad de acción autónoma del Estado se estanca si los programas comienzan a reducirse a los márgenes del compromiso entre los grupos que ejercen presión. Esto fue lo que habría ocurrido en el caso brasileño (Correa Weffort, Francisco, O Populismo na Politica Brasileira, Rio de Janeiro, Paz e Tierra, 1985, pp. 61-65). En el caso chileno, en cambio, como se argumenta en este artículo, es la fisura entre dos sub-regímenes de la acción estatal (uno financiado con los recursos del cobre y administrado de forma corporativa, otro financiado con impuestos menores a corto-plazo y gestionado por los gobiernos de turno) lo que finalmente dificultó la implementación de los programas sociales. La historiografía no ha puesto la atención debida a este fenómeno debido a que se asume que financiamiento fiscal es sinónimo de administración del Estado o intervencionismo. Así, como las políticas de fomento estaban financiadas con recursos del cobre, empréstitos externos y otra serie de impuestos, se asume que estas reflejarían la acción del Estado en la economía. En la práctica, la incidencia del poder ejecutivo y legislativo en estas políticas, que significaron enormes gastos fiscales, era más virtual que real. Además, en las otras
} 
Estas políticas de liberalización dan inicio a un nuevo ciclo histórico para derecha, en la que se comienzan a distinguir los grupos empresariales corporativistas, opuestos al plan de liberalización económica, y la nueva derecha monetarista. ${ }^{81} \mathrm{La}$ izquierda, por su parte, experimenta igualmente un proceso de re-organización, con la formación de la Central Única de Trabajadores en 1953 y el Frente de Unidad Sindical en 1956; entidades en las que se dio preferencia a una postura clasista, rechazando las alianzas con los denominados reformistas de centro ${ }^{82}$. El periodo del Estado desarrollista, basado supuestamente - en la cooperación entre diversos actores, provenientes de distintos sectores políticos y clases sociales, había llegado a su fin. ${ }^{83}$

\section{Consideraciones finales}

En el proceso de conformación de la Corfo, la base del Estado desarrollista chileno (1939-1954), convergieron dos posturas. Por un lado, la posición de los gremios empresariales, elaborada en los años post-crisis (1934-1938), basada en la creación una entidad financiada estatalmente, pero administrada noestatalmente; el postulado principal era que los recursos fiscales destinados al fomento no debían ser gestionados por intereses partidistas o doctrinas ideológicas. Por otro lado, estaba la postura de la centroizquierda, basada en la idea de un Estado desarrollista corporativo en el que los intereses de todos los sectores sociales debían estar plenamente representados; el postulado principal, en este caso, era que el fomento al sector privado favorecía también a la clase trabajadora.

Ambas posturas convergieron, pero - en la práctica - fueron los intereses de los sectores empresariales los que terminaron primando. Fueron los grupos empresariales los que lograron efectivamente posicionar como necesidad nacional o asesoramiento técnico, lo que inicialmente era un interés sectorial. La centro-izquierda ganó la batalla electoral, pero perdió la simbólico-política. Al intentar llevar a cabo su programa anti-imperialista, nacionalista y pro-obrero, terminó favoreciendo la implementación del plan político-empresarial. Por esta razón, el proyecto del Consejo de Economía Nacional, elaborado por la CPC en 1936-1938, pudo ser efectivamente llevado a cabo a pesar de convivir con gobiernos de centro-izquierda. El supuesto, defendido por dirigentes socialistas, comunistas o radicales, que el fomento al sector empresarial nacional era beneficioso también para la clase obrera, resultó ser fundamental en este proceso. Además, mediante la tesis de la cooperación, esta derrota simbólico-política terminó siendo invisibilizada.

En la presente investigación hemos planteado que, si se deja de lado esta tesis de cooperación, que más que una interpretación historiográfica, es inicialmente un supuesto de la misma centro-izquierda de aquellos años, es posible evidenciar que:

instancias en donde existía cierta incidencia para llevar a cabo otro tipo de programas, como las políticas sociales, los organismos estatales eran estériles y/o carentes de recursos.

${ }^{81}$ Correa, Sofía, "Algunos antecedentes históricos del proyecto neoliberal en Chile (1955-1958)", Revista del Centro de Estudios de la Realidad Contemporánea, número 6, 1986, pp. 106-146. Este proceso de transición ideológica, específicamente en el caso de la Sofofa, es tratado también en: Fernández, Joaquín y Goldflam, Margarita, "Hacia la constitución de una economía de mercados jerárquicos: Modernización capitalista y tradicionalismo social en los industriales chilenos (1952-1958)", Amérique Latine Histoire et Mémoire, número 32, 2016; López, Eduardo, "Del malestar a la amenaza: La Sociedad de Fomento Fabril y el populismo ibañista, 1950-1953”, Izquierdas, número 36, noviembre 2017, pp. 28-54.

82 Garcés y Milos, FOCH, CTCH, CUT, op. cit., pp. 87-122; Moulian, Tomás, "El gobierno de Ibáñez 1952-1958”, Programa FLACSO, número 2, 1986.

83 "La combinación del segundo de estos movimientos [jornada de protestas de julio de 1955] con el desborde inflacionario y la parálisis en las relaciones Ejecutivo-Congreso ha servido convencionalmente para demarcar el momento más crítico del trance". Ortega, op. cit., p. 133. 
1. En el periodo 1936-1938, la postura de los círculos empresariales transita desde la defensa de un Estado empresario comandado por un gobierno comprometido, a la idea que el problema no es el tipo de gobierno, ni la ideología, ni el partido, ni el presidente, sino el mismo poder ejecutivo/legislativo. La idea central era no tanto la de colaborar con la formación de un Estado moderno o empresario, como se suele aseverar, sino la de reducir al máximo la incidencia de los poderes ejecutivo/legislativo en la gestión de los recursos públicos destinados al fomento.

2. Representantes de sectores políticos diametralmente opuestos, coincidieron al afirmar que el proyecto de la Corfo significaba una reducción del campo de acción para los poderes ejecutivo/legislativo. Lo que caracteriza el denominado periodo desarrollista post-1939, no es tanto la formación del Estado empresarial - cuyos orígenes pueden datarse incluso hasta inicios del siglo XX - sino la consolidación de un modelo sustentado en la administración no-estatal de los recursos estatales; tal como propuso la CPC en 1936-1938. Esta tesis se complementa al revisar las numerosas redes indirectas de los círculos empresariales en el sector público, las que ponen en cuestión la idea del Estado desarrollista como un equilibrio de poderes. Paradójicamente, el supuesto intervencionismo del Estado desarrollista, era más recurrente en organismos en donde la incidencia real de los actores del Estado (poder ejecutivo/legislativo) era menor.

3. Contrariamente al Estado empresario, el Estado Social no estaba administrado por organismos corporativos semi-autónomos, como la Corfo, sino por los gobiernos de turno, los que tuvieron que enfrentar continuamente la no-cooperación tanto de la derecha en el parlamento como de los gremios empresariales. Tampoco estaba financiado - al menos hasta 1948 - con tributos al cobre o empréstitos extranjeros, sino con impuestos temporales, que con frecuencia resultaban insuficientes. Por esta razón, se tuvo que recurrir a los préstamos del Banco Central, provocando graves presiones inflacionarias. El des-financiamiento del Estado social y la ausencia da una política nacional de cooperación - situación diametralmente opuesta a la supuesta conciencia nacional existente en el Estado empresario - fue lo que finalmente desencadena la crisis inflacionaria. El Estado social, por tanto, no era excesivamente intervencionista, sino débil y carente de programas.

En resumen, la cooperación o el consenso nacional tuvieron lugar solamente en aquellas materias en las que los dirigentes del empresariado estuvieron de acuerdo; en el resto de los asuntos, como las políticas sociales, lo que primó fue el desacuerdo, la oposición, el bloqueo. Llama la atención que, desde la década de 1950, y hasta la actualidad, ciertas voces de la nueva derecha monetarista acusen al intervencionismo excesivo de los gobiernos de centro-izquierda como los causantes de la crisis, y que la misma centroizquierda - que ha mantenido en vida la tesis de la cooperación - se asuma como el principal gestor del Estado desarrollista. En la práctica, en aquellas instancias del Estado en donde la centro-izquierda tenía realmente alguna incidencia, el Estado era incapaz y carente de recursos; y en aquellas instancias en donde los círculos empresariales estaban realmente representados, fue donde el Estado tuvo mayorpeso. Sin embargo, se considera el periodo 1939-1952 como un periodo de irquierdas o un periodo de compromisos; esta creencia constituye, sin duda, una gran derrota histórica.

\section{Fuentes}

Banco Central de Chile, Memoria Anual del Banco Central de Chile

Banco Central de Chile, Boletín mensual

Bulnes, Luis, La corporación de fomento de la producción, Santiago, 1943.

Confederación de la Producción y el Comercio (CPC), La Confederación

Congreso Nacional de Chile (CNCh), Cámara de senadores: boletín de sesiones extraordinarias (BSE) 
Corporación de Fomento de la Producción (Corfo), Cinco años de labor. Santiago, Corfo, 1944

Corporación de Fomento de la Producción (Corfo), Diez años de labor, Santiago, Corfo, 1950

Corporación de Fomento de la Producción (Corfo), Memoria anual

Diario oficial de la República de Chile (DORCh)

El Andamio. Órgano de la Federación Sindical Libertaria de los Estucados y Ramos Similares

El Mercurio

Empresa Periodística de Chile, Diccionario Bibliográfico de Chile, Santiago, Empresa Periodística de Chile, 19381948

Partido Socialista de Chile, La Consigna. Semanario Oficial del Partido Socialista

Partido Socialista de Chile, Politica económica del Frente Popular. Santiago 1941

Rogers, Jorge, La Corporación de Fomento y la economía del futuro. Exposición leída en el consejo de la Corporación del día 25 de septiembre de 1944. Santiago, 1945

Sociedad de Fomento Fabril (Sofofa), Boletín de la Sociedad de Fomento Fabril

Sociedad Nacional de Agricultura, El campesino

Sociedad Nacional de Minería, Boletín minero

United Kingdom. Department of Overseas Trade, Report on economic and commercial conditions in Chile, London, 1936

\section{Bibliografía}

Ahumada, Jorge, En vez de la miseria, Santiago, Editorial del Pacífico, 1958.

Arellano, José, Politicas sociales y desarrollo 1924-1984, Santiago, CIEPLAN, 1985.

Arriagada, Ana María y Muñoz, Oscar, Los orígenes politicos y económicos del estado empresarial en Chile, Chile, CIEPLAN, 1977.

Bernedo, Patricio, "Prosperidad económica bajo Carlos Ibáñez del Campo, 1927-1929: la dimensión internacional de un programa económico de gobierno", Historia, no 105, 1989, 5-105

Casanova, Mauricio, Los orígenes del desarrollismo económico en Chile, Berlín, Universidad Libre de Berlín (Tesis doctoral), 2018.

Cavarozzi, Marcelo, The government and the industrial bourgeoisie in Chile: 1938-1964, Berkeley, University of California (Tesis doctoral), 1975.

Clark, Timothy David, The State and the Making of the Capitalist Modernity in Chile, Toronto, York University (tesis doctoral), 2012.

Collier, Simon y Sater, William, A History of Chile, 1808-1994, Cambridge, Cambridge University Press, 2012.

Correa, Sofía, "Algunos antecedentes históricos del proyecto neoliberal en Chile (1955-1958)", Revista del Centro

de Estudios de la Realidad Contemporánea, número 6, 1986, pp. 106-146.

Correa, Sofía, Con las riendas del poder, Santiago, Editorial Sudamericana, 2014.

ENDESA, Cincuenta años, Santiago 1993.

Correa Weffort, Francisco, O Populismo na Politica Brasileira, Rio de Janeiro, Paz e Tierra, 1985.

Fermandois, Joaquín, Fragmentos acerca del fin del mundo. Articulos y ensayos sobre Chile, Santiago, Centro de Estudios Bicentenario, 2015.

Fernández, Joaquín y Goldflam, Margarita, "Hacia la constitución de una economía de mercados jerárquicos: Modernización capitalista y tradicionalismo social en los industriales chilenos (1952-1958)", Amérique Latine Histoire et Mémoire, número 32, 2016.

French-Davis, Ricardo y Muñoz, Oscar, "Desarrollo económico, inestabilidad, y desequilibrios políticos en Chile 1950-89”, Colección de Estudios CIEPLAN, número 28, 1990, pp. 121-156.

Garcés, Mario y Milos, Pedro, FOCH, CTCH, CUT. Las centrales unitarias en la bistoria del sindicalismo cbileno, Santiago, ECO, Educación y Comunicaciones, 1988.

Garces, Mario, Movimiento obrero en la década del treinta y Frente Popular, Santiago, Tesis para optar al grado de Licenciatura en Historia (Pontificia Universidad Católica de Chile), 1985, pp. 68-161.

Garreto $\square$ n, Manuel, El proceso pol $\square$ tico chileno, Santiago, Ediciones Minga, 1983. 
Guajardo Soto, Guillermo, "Las empresas públicas chilenas: una historia de diversidad, crisis y continuidad, 1811-2010" en Historia política de Chile, 1801-2010. Tomo III: problemas económicos, Chile, FCE Chile, 2018, pp. 315-344.

Henríquez, Rodrigo, En estado sólido: politicas y politización en la construcción estatal. Chile 1920-1950, Santiago, Ediciones PUC, 2014.*

Ibáñez Santa María, Adolfo, "Los ingenieros, la política y la política en Chile: del ministerio de fomento a la Corporación de Fomento de la Producción 1927-1939”, Historia, número 18, 1983, pp. 45-102.

Ibáñez, Santa María, Adolfo, "El liderazgo de los gremios empresariales y su contribución al desarrollo del Estado moderno durante la década de 1930”, Historia, número 28. 1994, pp. 183-216.

Joselyn-Holt, Alfedro, Correa, Sofía; Figueroa, Consuelo; Rolle, Claudio; y Vicuña, Manuel, Historia del siglo XX chileno, Santiago, Editorial Sudamericana, 2001.

López, Eduardo, "Del malestar a la amenaza: La Sociedad de Fomento Fabril y el populismo ibañista, 19501953”, Izquierdas, número 36, noviembre 2017, pp. 28-54.

Meller, Patricio, Un siglo de economía politica chilena 1890-1990, Santiago, Editorial UAB, 1998.

Milos, Pedro, Frente Popular en Chile. Su configuración: 1935-1938. Santiago, LOM, 2008.

Ministerio de Planificación y Cooperación, "Evolución de las políticas sociales en Chile 1921-1991", Documentos sociales MIDEPLAN, 1991.

Montero, Cecilia, La revolución empresarial chilena, Santiago, BPR Publishers, 1997.

Moulian, Tomás, "Desarrollo político y Estado de compromiso. Desajustes y crisis estatal en Chile", Colección de Estudios CIEPLAN, número 64, 1982, pp. 105-158.

Moulian, Tomás, El gobierno de Ibáñez 1952-1958, Santiago, Programa FL ACSO (número 2), 1986.

Moulian, Tomás, Fracturas: de Pedro Aguirre Cerda a Salvador Allende (1938-1973). Santiago, LOM, 2006.

Nazer, Ricardo, "La Corporación de Fomento de la Producción y la modernización económica en Chile 19391970”, Revista de gestión pública, volumen V, número 2, 2016, pp. 283-316.

Ortega, Luis, Corfo: cincuenta años de labor, Santiago, Corfo, 1990.

Ortega, Luis, "La economía política de la industrialización a través de un siglo" en Jaksic, Iván; Estefane, Andrés; Robles, Claudio (eds.), Historia politica de Chile, 1801-2010. Tomo III: problemas económicos, Chile, FCE Chile, 2018, pp. 141-170.

Pinto, Anibal, Chile, un caso de desarrollo frustrado, Santiago, Editorial Universitaria, 1973.

Pinto, Julio y Salazar, Gabriel, Historia contemporánea de Chile III. La economía: mercados, empresarios y trabajadores, Santiago, LOM, 2002.

Rengifo, Francisca, "El estado de seguridad social chileno y la institucionalización desigual del bienestar" en Rengifo, Francisca y Jaksic, Iván (eds.), Historia política de Chile, 1810-2010. Tomo II: Estado y sociedad, Chile, FCE Chile, 2017, pp. 397-424.

Rodríguez Weber, Javier, La economía política de la desigualdad del ingreso en Chile 1850-2009, Montevideo, Universidad de la República ('Tesis doctoral), 2014.

Silva, Patricio, Estado, neoliberalismo y politica agraria en Chile, 1973-1981, Amsterdam, CEDLA, 1987.

Silva, Patricio, In the name of reasons: technocrats and politics in Chile, Philadelphia, The Pennsylvania State University Press, 2009.

Vergara Marshall, Ángela, “Estado, trabajo y trabajadores”, en Rengifo, Francisca y Jaksic, Iván (eds.), Historia politica de Chile, 1810-2010. Tomo II: Estado y sociedad, Chile, FCE Chile, 2017, pp. 365-396.

Villalobos, Sergio y Sagredo, Rafael, Elproteccionismo económico en Chile. Siglo XIX, Santiago, Instituto Blas Cañas, 1987.

Vitale, Luis, Interpretación marxista de la historia de Chile. España, Fontamara, 1980. 